\title{
Antiphosphatidylserine Antibodies in Patients With Autoimmune Diseases and HIV-Infected Patients: Effects of Tween 20 and Relationship With Antibodies to $\beta 2$-Glycoprotein I
}

\author{
Concepción González, ${ }^{1,2}$ Antonio Lestón, ${ }^{1}$ Belén García-Berrocal, ${ }^{1}$ \\ Angel Sánchez-Rodriguez, ${ }^{3,5}$ José A. Martín-Oterino, ${ }^{3}$ Ignacio Alberca, ${ }^{4}$ \\ Miguel Cordero, ${ }^{3,5}$ Ramón Jorge ${ }^{3}$ José A. Navajo, ${ }^{1}$ and José M. González-Buitragoo ${ }^{1,2 *}$ \\ ${ }^{1}$ Servicio de Bioquímica, Hospital Universitario, Salamanca, Spain \\ ${ }^{2}$ Departamento de Bioquímica y Biología Molecular, Universidad de Salamanca, Salamanca, Spain \\ ${ }^{3}$ Servicio de Medicina Interna, Hospital Universitario, Salamanca, Spain \\ ${ }^{4}$ Servicio de Hematología, Hospital Universitario, Salamanca, Spain \\ ${ }^{5}$ Departamento de Medicina, Universidad de Salamanca, Salamanca, Spain
}

\begin{abstract}
Antiphospholipid antibodies (aPL) react with negatively charged phospholipids, which may often be complexed with a protein cofactor such as $\beta 2$ glycoprotein ( $\beta 2 \mathrm{GPI}$ ) and prothrombin. Cofactor requirements may be assessed by measuring antibodies to $\beta 2 \mathrm{GPI}$ or by adding Tween 20 to some reagents in the assays for aPL (anticardiolipin and antiphosphatidyIserine). We have measured anticardiolipin antibodies (aCL), antiphosphatidylserine antibodies (aPS), and anti $\beta 2$ glycoprotein antibodies (aß2GPI) in the serum of 10 normal subjects, 20 patients with systemic autoimmune diseases (SAD) diagnosed as having systemic lupus erythematosus (SLE) or antiphospholipid syndrome (APS), and 12 patients with HIV infection. Adding Tween 20 to aPS, the assay couldn't differentiate protein cofactor dependent from independent antibodies, but this can be done by measuring aß2GPI
\end{abstract}

$(P=0.0008)$. There was a significant correlation between aCL and $\mathrm{a} \beta 2 \mathrm{GPI}$ in the control group and in the patients with SAD, but not in the HIV-positive (HIV+) patients. After excluding the HIV+ patients, the best Spearman correlation was obtained between a $\beta 2 \mathrm{GPI}$ and aCL $(0.64, P<0.0005)$. In 3 out of 7 patients with positive aß2GPI and in 5 out of 6 patients with moderate or high positive aCL of the group of SAD, there was a history of venous thrombosis. The presence of moderate or high values of aCL either alone or together with aß2GPI was significantly associated with a history of venous thrombosis $(P$ $<0.05$ ). Moderate or high aCL concentrations and their association with aß2GPI seems to be useful for the assessment of the risk of venous thrombosis in unselected patients with SLE or APS. J. Clin. Lab. Anal. 13:59-64, 1999. ( 1999 Wiley-Liss, Inc.

Key words: antiphosphatidylserine antibodies; anticardiolipin antibodies; anti $\beta 2$ glycoprotein antibodies; autoimmune diseases; HIV infection

\section{INTRODUCTION}

Antiphospholipid antibodies (aPL) are a family of closely related immunoglobulins that react with negatively charged phospholipids, which may often be complexed with a protein cofactor such as $\beta 2$-glycoprotein ( $\beta 2 \mathrm{GPI})$ and prothrombin. The negatively charged phospholipids against antibodies that have been measured are: cardiolipin (aCL), phosphatidic acid, phosphatidylserine (aPS), and phosphatidylinositol (1). The presence of aPL is associated with a disorder termed antiphospholipid syndrome (APS) characterized by thrombocytopenia, recurrent thromboembolic phenomena, recurrent fetal loss, and other diverse manifestations (2-5). The APS is often present in subjects with systemic autoimmune diseases (SAD) such as systemic lupus erythematosus (SLE), and in subjects without an underlying autoimmune disease. Also, aPL may be present in subjects with infectious diseases such as syphilis and HIV infection, although these infectious diseases are not usually associated with APS $(6,7)$.

The phospholipid-binding plasma protein, $\beta 2 \mathrm{GPI}$ is the antigenic target of autoantibodies in patients with SAD whereas in patients with syphilis and others infectious diseases, aCL antibodies are detected in absence of seric proteins, and its binding is inhibited very little by added bovine

*Correspondence to: J.M. González-Buitrago, Ph.D., Servicio de Bioquímica, Hospital Universitario, 37007 Salamanca, Spain. E-mail: buitrago@ gugu.usal.es

Received 18 February 1998; Accepted 29 September 1998 
$\beta 2 \mathrm{GPI}$ (2). The dependence of aPL on a protein cofactor such as $\beta 2 \mathrm{GPI}$ or prothrombin, has been proposed as a means to differentiate between aPL present in APS and aPL present in infectious diseases (8-11). Also, it has been suggested that adding Tween 20 to some ELISA reagents can distinguish between GPI-dependent (those found in APS) and GPI-independent (those found in infectious diseases) anticardiolipin antibodies (12).

The aim of the present study was to assess: (1) the effect of Tween 20 on aPS measured by ELISA; (2) if the relationship between aCL and aPS is modified by Tween 20 addition on aPS assay; and (3) the relationship between aPL and $\beta 2 \mathrm{GPI}$ antibodies (aß2GPI).

\section{Subjects, Materials, and Methods}

\section{Subjects}

The subjects were seen at the Departments of Internal Medicine and Hematology of the University Hospital of Salamanca where their diagnoses were made. They were divided in three groups: healthy blood donors $(\mathrm{n}=10)$, all men (ranged 8-25 years); HIV-positive (HIV+) patients with $\mathrm{aCL}>80 \mathrm{GPL} / \mathrm{ml}(\mathrm{n}=12), 5$ women and 7 men (ranged 1937 years); and patients with $\operatorname{SAD}(\mathrm{n}=20), 14$ women and 6 men (ranged 24-64 years). SLE was diagnosed in 17 patients, according to the American College of Rheumatology criteria (13). Seven patients with SAD had a past history of venous thrombosis and fullfilled Harris criteria for APS (14). Four patients had APS arising from their SLE and three had primary APS. In ten patients with SLE, the existence of thromboembolism was clinically excluded. In three patients the clinical history doesn't include antecedents of venous thrombosis but it couldn't be totally excluded. In three HIV+ patients an acquired immunodeficiency syndrome was diagnosed, and in two other HIV+ patients thromboembolic phenomena were detected, one associated with a factor V Leyden deficiency and the other associated with serum aPL.

Blood samples were obtained after an overnight fast and allowed to coagulate at room temperature. Serum was obtained by centrifugation and an aliquot was frozen at $-20^{\circ} \mathrm{C}$ until assayed.

\section{ELISA for $\lg G$ antiphosphatidylserine antibodies}

aPS antibodies of IgG isotype were measured by a commercial ELISA technique (Reads Medical Products, CO, USA) that uses bovine phosphatidylserine as antigen and bovine serum as the source of $\beta 2$ GPI in the sample diluent. Samples, calibrators, and controls were 50-fold diluted in sample diluent and applied to the wells. Bound antibodies were detected using horseradish peroxidase-labeled antibodies against human IgG. Interassay coefficients of variation (CV) were $8.3 \%$ and $6.9 \%$ for low (< $10 \mathrm{GPS} / \mathrm{mL}$ ) and high (40 GPS/ $\mathrm{mL}$ ) aPS concentrations, respectively. To assess the effect of
Tween 20 on APS measurement, we replaced washing buffer by $0.05 \%$ Tween $20 /$ washing buffer and sample diluent by $0.05 \%$ Tween 20/sample diluent. Samples were read at 450 $\mathrm{nm}$ and concentrations expressed as GPS units $/ \mathrm{mL}$. These units are traceable to the reference preparations of Louisville Antiphospholipid Laboratory. Reference values were obtained in our laboratory and did not differ from those recommended by the manufacturer (mean $+3 \mathrm{SD}$ ), $16 \mathrm{GPS} / \mathrm{mL}$.

\section{ELISA for IgG anticardiolipin antibodies}

$\mathrm{aCL}$ antibodies of $\mathrm{IgG}$ isotype were measured by using a commercial ELISA technique (Chesire Diagnostic Limited, Chester, England). Plates were coated by cardiolipin and blocked with a $\beta 2$ GPI solution. This cofactor was also added in the sample diluent $(20 \mu \mathrm{g} / \mathrm{mL})$. Standards are expressed as $\mathrm{GPL} / \mathrm{mL}$ according to aCL International Standard. Alkaline phosphatase conjugated IgG antibody was the secondary antibody and p-nitrophenyl phosphate the substrate. The absorbance was measured by an optical reader at $405 \mathrm{~nm}$. Interassay $\mathrm{CV}$ were $10.5 \%$ and $7.8 \%$ for $9.5 \mathrm{GPL} / \mathrm{mL}$ and $32.0 \mathrm{GPL} / \mathrm{mL}$ concentrations, respectively. The reference cut-off (13 GPL/ $\mathrm{mL}$ ) was calculated as the mean GPL antibody concentration of 130 healthy blood donors plus three standard deviations.

\section{ELISA for IgG anti $\beta 2$ GPI antibodies}

aß2GPI of IgG isotype were measured by Quanta Lite $\beta 2$ GPI assay (Inova Diagnostic, Inc., San Diego, CA). Irradiated plates were coated with purified $\beta 2 \mathrm{GPI}$ and stabilized. $100 \mu \mathrm{L}$ of prediluted calibrator and control and $100 \mu \mathrm{L}$ of $1 /$ 101 diluted samples were added to each well. Standards were referenced to the reference standards available from the Rheumatology Laboratory, Seton Hall University, St. Joseph's Hospital and Medical Centre (15). Antihuman IgG horseradish peroxidase labelled conjugate was used. Interassay $\mathrm{CV}$ were $4.3 \%$ and $3.5 \%$ for negative $(18.9 \mathrm{U} / \mathrm{mL})$ and high reactive $(82.4 \mathrm{U} / \mathrm{mL})$ samples, respectively. Manufacturer recommended negative range values $0-20 \mathrm{U} / \mathrm{mL}$.

All the ELISAS were automated in a Guest System (Chemila, Menarini, Italy).

\section{Statistical methods}

The results were analyzed by a commercial statistic program (SPSS) on a personal computer. Nonparametric descriptive statistics, median and interquartilic range, were used. Kruskal-Wallis and Wilcoxon tests allowed comparison of antibody concentrations obtained in each of the groups. Kappa Statistic was applied to evaluate the agreement (positive/negative) between tests. The Binomial Exact Test was used to evaluate the association between the presence of antibodies and clinical history of the patient. The Spearman's Rank Correlation Test was used to assess the relationship between the values of the antibodies measured. Finally, the relationship 
between aPS and aPSTween 20 concentrations were examined using linear regression analysis.

\section{RESULTS}

aPS concentrations were elevated in patients with both SAD and HIV infection with respect to the control subjects $(P<$ $0.00005)$. aPSTween 20 values were higher than aPS values in the three groups studied $(P<0.001)$ (Table 1$)$. When both the difference (aPSTween20-aPS) and the ratio aPSTween20/ aPS were analyzed, greater values were obtained in HIV+ patients and patients with APS than in both patients with SLE and control subjects $(P<0.00005$ for the difference and $P=$ 0.0064 for the ratio) (Fig.1). However, neither the difference nor the ratio changed between patients with APS and HIV+ patients (NS). The regression analysis showed a positive linear relationship between aPSTween 20 and aPS concentrations (Fig. 2). Thus, 94\% aPSTween 20 values may be explained as a function of the initial aPS concentration of the specimen, and an increase of $1.56 \mathrm{GPS} / \mathrm{mL}$ aPSTween 20 for each GPS/ $\mathrm{mL}$ aPS is expected when adding detergent.

The number of specimens classified as positive for aPSTween20 with respect to aPS did not change in the patients with SAD (7/20), while a positive result was obtained in the control group (1/10), and all results were positive for aPSTween20 in the HIV+ patients (12/12) (Table 1). The normal crossing point for aPS is $16 \mathrm{GPS} / \mathrm{mL}$ and the corrected crossing point according to the regression line for aPSTween 20 was 25 GPS/mL. The agreement between aPS and aPSTween 20 measurements was 0.73 (IC kappa, 95\%: 0.53 to 0.92 ). aPS and aPSTween 20 were present in the serum in most of the samples with aCL and there was a good correlation for both aCL vs. aPS $\left(r^{2}=0.91\right)$ and aCL vs. aPSTween 20 values $\left(r^{2}=0.97\right)$.
We did not find any a $\beta 2 \mathrm{GPI}$ in the serum of the control group $(0 / 10)$ or in the serum of the HIV+ patients $(0 / 10)$. Two HIV+ patients with thromboembolic events were excluded. In one patient there was a factor V Leyden deficiency and in the other there was no other alteration of coagulation than the presence of aPL. In 7/20 of the patients with SAD, aß2GPI was found, 5/9 with aCL(+), and 2/11 with aCL(-) (Table 2). After excluding HIV+ patients, the following Spearman correlation coefficients were obtained: a 32 GPI vs. aCL $(0.64, P<0.0005)$, a 2 GPI vs. aPS $(0.45, P<0.0005)$, and aß2GPI vs. aPSTween20 (0.58, $P<0.001)$.

Although in patients with APS there was an increased a 32 GPI prevalence (3/7) with regard to the control group ( $0 /$ 10) $(P=0.05$, Fisher exact test $)$ a 32 GPI also was detected in 4/10 patients with SLE without thrombosis (SLE/T-) (Table 3). Of all the antibodies studied, a significant association was only obtained between moderate or strong aCL(+) and APS, as can be seen in Table 3 . The combination of either moderate or strong aCL(+) and aß2GPI increases specificity but decreases sensitivity (Table 3 ).

\section{DISCUSSION}

Antiphospholipid antibodies comprise a wide spectrum of antibodies that react in the analysis systems that use phospholipids. In patients affected with autoimmune diseases such as SLE and APS, aCL and aPS appear to crossreact $(16,17)$. This fact could justify the good correlation obtained in this study. Either aPS or antiphosphatidylinositol antibodies are more prevalent than aCL in a few patients (18). All patients with elevated aPS also had high aCL in the present study.

Currently, it is accepted that the aCL test detects a $\beta 2$ GPI, $\mathrm{aCL}$, and antibodies against other serum proteins (which bind to cardiolipin to a lesser extent) and, in general, phospholip-

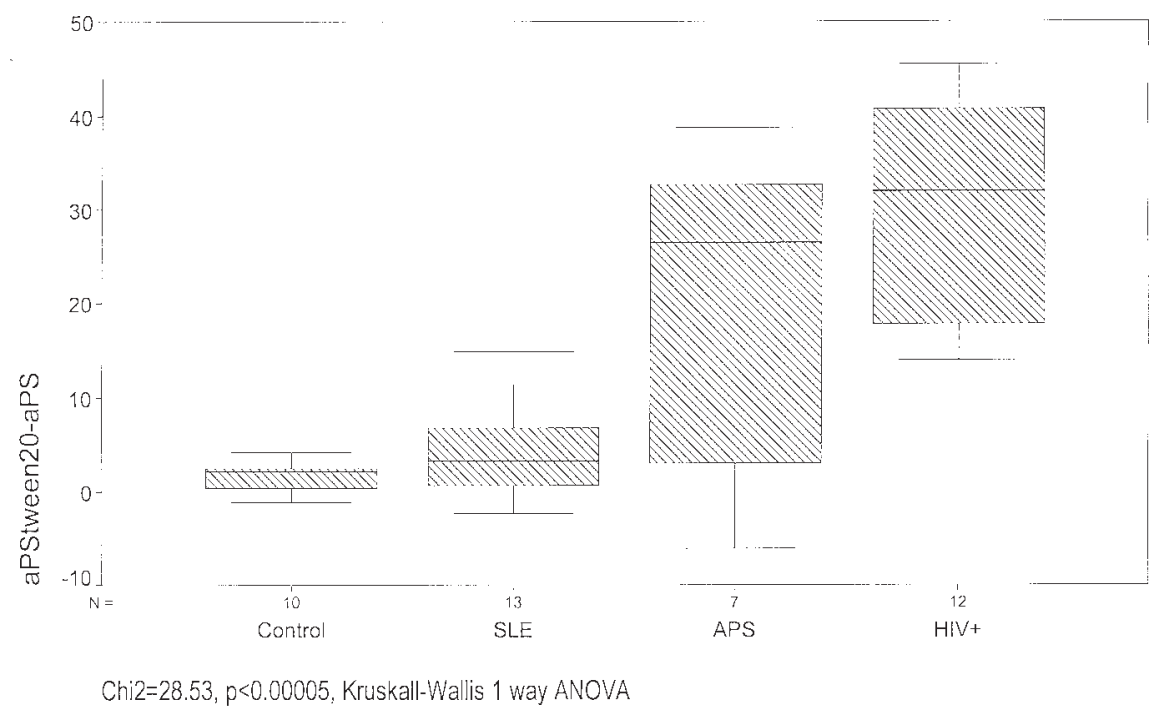

Fig. 1. Box-plot for differences in aPS serum concentrations when Tween 20 is added. $\chi^{2}=28.53, P<0.00005$, Kruskall-Wallis 1 way ANOVA. 


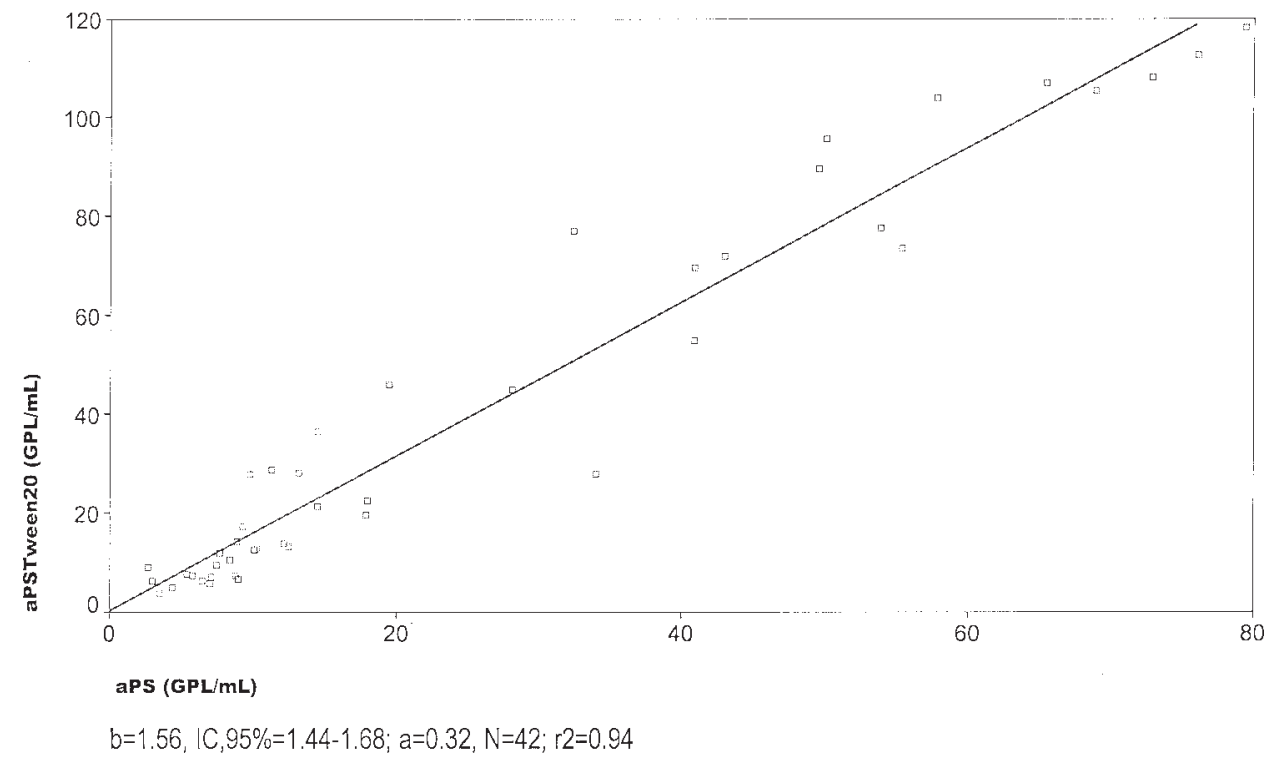

Fig. 2. Relation between aPS concentrations obtained in the presence and absence of Tween $20: \mathrm{b}=1.56, \mathrm{IC}, 95 \%=$ $1.44-1.68 ; \mathrm{a}=0.32 ; \mathrm{n}=42 ; \mathrm{r}^{2}=0.94$.

ids. In the patients with SAD, antibodies are mainly directed against $\beta 2 \mathrm{GPI}$, which binds with a high protein density to anionic surfaces of phospholipids. While in patients with syphilis and other infectious diseases, aCL is detected in the absence of serum proteins, and its binding is less inhibited by bovine $\beta 2$ GPI added in most of tests (19). Adding detergent Tween 20 in the ELISA reagents has been proposed as a method to distinguish $\beta 2 \mathrm{GPI}$-dependent and $\beta 2 \mathrm{GPI}$-independent $\mathrm{aCL}$ (12). In the present study, we added Tween 20 to the sample diluent and the washing solution in the ELISA for aPS, and we found that aPS concentration increased in all the groups studied. However, we didn't find that detergent addition allowed us to distinguish $\beta 2 \mathrm{GPI}$-dependent (SAD) and $\beta$-independent (HIV infection) aPS. The detergent effect seems to

TABLE 1. aPS, aPSTween20, and aCL Distributions ${ }^{\mathrm{a}}$

\begin{tabular}{lcccc}
\hline & $\begin{array}{c}\text { Total } \\
\mathrm{n}=44\end{array}$ & $\begin{array}{c}\text { Control } \\
\mathrm{n}=10\end{array}$ & $\begin{array}{c}\text { SAD } \\
\mathrm{n}=20\end{array}$ & $\begin{array}{c}\text { HIV+ } \\
\mathrm{n}=12\end{array}$ \\
\hline aPS & 12.85 & $7.35^{*}$ & $12.85^{*}$ & $48.08^{*}$ \\
GPS/mL & $(34.60)$ & $(4.72)$ & $(10.30)$ & $(28.38)$ \\
& 19 & 0 & 7 & 11 \\
aPSTween20 & 21.90 & $9.10^{\wedge}$ & $18.40 \cdot$ & $78.28 !$ \\
GPS/mL & $(64.07)$ & $(6.90)$ & $(25.50)$ & $(45.55)$ \\
& 21 & 1 & 7 & 12 \\
aCL & 13.95 & 5.3 & 12.3 & 196.8 \\
GPL/mL & $(115.6)$ & $(3.30)$ & $(31.43)$ & $(135.1)$ \\
& 21 & 0 & 9 & 12 \\
\hline
\end{tabular}

${ }^{a}$ Results are expressed as median (interquantilic range), and positive results. $* \chi^{2}=18.58, P<0.00005$, Kruskal-Wallis Test. aPSTween 20 vs. aPS in control^ ${ }^{\wedge}(\mathrm{z}=2.67, P<0.00005), \mathrm{SAD} \cdot(\mathrm{z}=3.3, P=0.0007), \mathrm{HIV}+$ ! ( $=$ $5.17, P<0.00005)$, Wilcoxon Test. The SAD group includes patients with systemic lupus erythematosus and patients with antiphospholipid syndrome. be a function of initial concentration of aPS. It has been demonstrated by other authors that Tween 20 addition to buffer washing solution potentiates a $\beta 2$ GPI binding to $\beta 2$ GPI in the patients with SLE (5).

In HIV+ patients we have not observed the presence of aß2GPI in serum, in spite of high concentrations of aCL. These results are in agreement with the fact that antiphospholipid antibodies react with phospholipids in a protein cofactor independent way. Similar results were obtained in patients with syphilis (9). When patients whose aCL can be considered as cofactor-independent were excluded, a significant correlation $(r=0.64)$ between aCL and aß2GPI was obtained; although it was lower than that obtained by other authors, in patients with either APS $(0.90)$ or SLE $(0.79)(8,9)$. The correlation coefficient decreased when aPS were considered, especially when Tween 20 was not added. This fact could indicate that $\beta 2 \mathrm{GPI}$ is not so important as an aPS cofactor as it is for aCL, perhaps because there were a greater binding of other proteins to phosphatidylserine.

In patients with SAD, the presence of antiphospholipid antibodies detected as lupus anticoagulant or with aCL tests

TABLE 2. Association Between aß2GPI and $\mathrm{aCL}^{\mathrm{a}}$

\begin{tabular}{lcccc}
\hline & $\begin{array}{c}\text { Control } \\
(\mathrm{aCL}-)\end{array}$ & $\begin{array}{c}\mathrm{SAD} \\
(\mathrm{aCL}-)\end{array}$ & $\begin{array}{c}\mathrm{SAD} \\
(\mathrm{aCL}+)\end{array}$ & $\begin{array}{c}\mathrm{HIV}+ \\
(\mathrm{aCL}+)\end{array}$ \\
\hline aß2GPI- & 10 & 9 & 4 & 10 \\
aß2GPI+ & 0 & 2 & 5 & 0 \\
Total & 10 & 11 & 9 & 40 \\
\hline
\end{tabular}

${ }^{\mathrm{a}} \mathrm{SAD}$ group includes patients with SLE and patients with APS. $\chi^{2}=12.71$, $P=0.0053$, Kruskal-Wallis Test. SAD(aCL+) vs. SAD(aCL-), $P=$ NS (Binomial Test). Two HIV+ patients and thromboembolic events were excluded. 
TABLE 3. Prevalence of aPL and aß2GPI in Patients With SLE Without Clinical History of Thrombosis and Patients With Thrombosis and APS

\begin{tabular}{lccc}
\hline & $\begin{array}{c}\text { SLE (T-) } \\
\mathrm{n}=10\end{array}$ & $\begin{array}{c}\text { APS } \\
\mathrm{n}=7\end{array}$ & $\begin{array}{c}P \\
\text { Fisher }\end{array}$ \\
\hline $\mathrm{a} \beta 2 \mathrm{GPI}>20 \mathrm{U} / \mathrm{mL}$ & 4 & 3 & $\mathrm{NS}$ \\
$\mathrm{aCL}>13 \mathrm{GPL} / \mathrm{mL}$ & 4 & 5 & $\mathrm{NS}$ \\
$\mathrm{aCL}>20 \mathrm{GPL} / \mathrm{mL}$ & 1 & 5 & 0.02 \\
$\mathrm{aPS}>16 \mathrm{GPS} / \mathrm{mL}$ & 3 & 4 & $\mathrm{NS}$ \\
$\mathrm{aPST} w e e n 20>25 \mathrm{GPS} / \mathrm{mL}$ & 5 & 6 & $\mathrm{NS}$ \\
$\mathrm{aCL}>20 \mathrm{GPL} / \mathrm{mL}$ & 0 & 3 & 0.05 \\
$\mathrm{Y}$ a $\beta 2 \mathrm{GPI}>20 \mathrm{U} / \mathrm{mL}$ & & & \\
\hline
\end{tabular}

is associated with venous thromboembolic phenomena. In this work aCL were detected in 9/20 of the patients with SAD, and in $6 / 20$ (five of them with aCL greater than $40 \mathrm{GPL} / \mathrm{mL}$ ) when only > $20 \mathrm{GPL} / \mathrm{mL}$ values were considered. There were clinical antecedents of thrombosis with a significant association in 5/6 of these patients, which also has been demonstrated by others $(2,3)$. Prevalence of a $\beta 2$ GPI was increased $(5 / 9)$ in patients with $\mathrm{SAD} \mathrm{aCL}(+)$ and was greater than in patients with SAD aCL(-) (2/11), although without statistical significance. Forastiero et al. have described greater prevalences in SLE patients and venous thromboembolic phenomena (9). The degree of prevalence seems to depend on aCL concentration and the number of patients with thrombosis, because when antecedents of $\mathrm{aCL}(+)$ and thrombosis were taken into account, $4 / 5$ patients have positive aß2GPI. Roubey et al. think that a 32 GPI are more associated with venous thrombosis than aCL, and that they have greater positive predictive value (14\% vs. $35 \%$ ) (20). In our study, however, when results obtained for aCL were not taken into account, patients with APS (3/7) didn't have aß2GPI more prevalent than patients without thrombosis, since it was detected in 4/10 SLE patients without thrombosis, 2 of them with aCL (+) and the other 2 with aCL (-). It is possible that these patients could develop a thromboembolic phenomenon in the future (21), or perhaps the cut-off should be elevated, with respect to that recommended by the manufacturer, to increase specificity as was done with aCL. However, some authors, such as Emlen, suggest that only approximately one third of the patients with SLE and a 32 GPI will have a clinical history of thrombosis (22). However, in order to detect venous thromboembolic phenomena in patients with SAD, in our study the best sensitivity was obtained with aCL at moderate or high levels, and the best specificity when aCL is associated with aß2GPI measurement.

In summary, in the ELISAs for measurement of aPS that include $\beta 2$ GPI as a cofactor, adding of Tween 20 potentiates the binding of aPL to phosphatidylserine. However, this addition doesn't allow to differentiate $\beta 2 \mathrm{GPI}$-dependent from $\beta 2 \mathrm{GPI}$-independent aPS. Results obtained for aPS and aCL were correlated and they agreed in a high number of assayed samples of both the patients with SAD and controls. More- over, in these groups there was a significant correlation between aPL analyzed and a $\beta 2$ GPI. In $3 / 7$ patients with SAD (aß2GPI+) there were clinical thrombotic events, in spite of it not being possible to rule out a late development of thrombotic events in the rest of the patients. In our study and for autoimmune diseases (SLE and APS), the best sensitivity to identify the patients affected by venous thrombosis has been obtained with aPL(aCL) at moderate to high concentrations, whereas the best specificity has been obtained when both positive aPL(aCL) and aß2GPI were obtained.

\section{REFERENCES}

1. Asherson RA, Cervera R. Antiphospholipid syndrome. J Invest Dermatol 1993;100:21S-27S.

2. Hughes GRV. The antiphospholipid syndrome: Ten years on. Lancet 1993;342:341-344.

3. Mcneil HP, Chesterman CN, Krilis SA. Immunology and clinical importance of antiphospholipid antibodies. Adv Immunol 1991; 49:193-280.

4. Triplett DA. Antiphospholipid antibodies and thrombosis. A consequence, coincidence, or cause? Arch Pathol Lab Med 1993;117:78-88.

5. Puurunen M, Vaarala O, Julkunen H, Aho K, Palosuo T. Antibodies to phospholipid binding proteins and occurrence of thrombosis in patients with systemic lupus eritematosus. Clin Immunol Immunopathol 1996;80:16-22.

6. Coll Daroka A, Gutierrez-Cebollada J, Yazbeck H, Berges A, RubiesPrat J. Anticardiolipin antibodies and adquired immunodeficiency syndrome: Prognostic marker or association with HIV infection. Infection 1992;20:140-142.

7. Capel P, Janssens A, Clumeck N, Gerard M, Feremans W, Vamdevelde D, Fondu P. Anticardiolipin antibodies (ACA) are most often not associated with lupus-like anticoagulant (LLAC) in human immunodeficiency virus (HIV) infection. Am J Hematol 1991;37:234-238.

8. Tsutsumi A, Matsuura E, Ichikawa K, Fujisaku A, Mukkiu M, Kobayashi $\mathrm{S}$, Koike T. Antibodies to beta-2 glycoprotein I and clinical manifestations in patients with systemic lupus erythematosus. Arthritis Rheum 1996;39:1466-1474, 1996.

9. Forastiero RR, Matinuzzo M, Kordich LC, Carreras LO. Reactivity to beta-2 glycoprotein I clearly differentiates anticardiolipin antibodies from antiphospholipid syndrome and syphilis. Thromb Haemost 1996;75:717-720.

10. McNeil HP, Simpson RJ, Chesterman CN, Krilis SA. Antiphospholipid antibodies are directed against a complex antigen that includes a lipidbinding inhibitor of coagulation: Beta-2 glycoprotein I (apolipoprotein H). Proc Natl Acad Sci U S A 1990;87:4120-4124.

11. Cines DB, McCrae KM. The antiphospholipid-protein syndrome. J Clin Immunol 1995;15:86S-98S.

12. Matsuda J, Saitoh N, Gohghi K, Gotoh M. Distinguishing beta-2 glycoprotein I dependent (systemic lupus erythematosus type) and independent (syphilis type) anticardiolipin antibody with Tween 20. Br J Haematol 1993;85:799-802.

13. Tan EM, Cohen AS, Fries JF, et al. The 1982 revised criteria for the classification of systemic lupus erythematosus. Arthritis Rheum 1982;25:1271-1277.

14. Harris EN. Annotation: Antiphospholipid antibodies. Br J Haematol 1990;74:1-9.

15. Erickson E, Najmey S, Keil L, El-Kadi H, DeBari V. Reference calibrators for IgG antibodies to $\beta 2$-glycoprotein I: Preparation, properties and availability to investigators. Clin Chem 1996;42:1-2.

16. Reyes H, Dearing L, Peter JB. Antiphospholipid antibodies. A critique of their heterogeneity and hegemony. Sem Thromb Hemostasis 1993;20:89-100. 


\section{González et al.}

17. Yodfat O, Blank M, Krause I, Shoenfeld Y. The pathogenic role of antiphosphatidylserine antibodies: Active immunization with the antibodies leads to the induction of antiphospholipid syndrome. Clin Immunol Immunopathol 1996;78:14-20.

18. Arfors L, Lefvert AK. Enrichment of antibodies against phospholipids in circulating immune complexes (CIC) in the anti-phospholipid syndrome (APLS). Clin Exp Immunol 1997;108:47-51.

19. Roubey RAS. Immunology of the antiphospholipid antibody syndrome. Arthritis Rheum 1996;39:1444-1454.
20. Roubey RAS, Maldonado MA, Byrd SN. Comparison of an enzymelinked immunosorbent assay for antibodies to $\beta 2$-glicoprotein I and a conventional anticardiolipin immunoassay. Arthritis Rheum 1996;39: 1606-1607.

21. Pengo V, Biasiolo A, Brocco T. Autoantibodies to phospholipid-binding proteins in patients with thrombosis and phospholipid-reactive antibodies. Thromb Haemost 1996;75:721-724.

22. Emlen W. Antiphospholipid antibodies: New complexities and new assays. Arthritis Rheum 1996;39:1441-1443. 